\title{
The Accuracy of Kidney Injury Molecule-1 for Earlier Diagnosis Acute Kidney Injury in Polytrauma
}

\author{
Tinni Trihartini Maskoen ", Budiana Rismawan, Rangga Saputra \\ Department of Anesthesiology and Intensive Therapy, Faculty of Medicine Universitas Padjadjaran, Dr. Hasan Sadikin Hospital, Bandung, \\ West Java, Indonesia \\ Email address: \\ ttmaskoen@yahoo.co.id (T. T. Maskoen) \\ ${ }^{*}$ Corresponding author
}

\section{To cite this article:}

Tinni Trihartini Maskoen, Budiana Rismawan, Rangga Saputra. The Accuracy of Kidney Injury Molecule-1 for Earlier Diagnosis Acute Kidney Injury in Polytrauma. Science Journal of Clinical Medicine. Vol. 8, No. 5, 2019, pp. 49-53. doi: 10.11648/j.sjcm.20190805.11

Received: July 22, 2019; Accepted: August 28, 2019; Published: September 17, 2019

\begin{abstract}
Multiple trauma often causes acute kidney injury (AKI) and is one of the most common causes of death in the world. Multiple trauma is a severe injury to an organ that is followed or accompanied by injury to other organs with injury severity score $\geq 16$ causing hypovolume, hypoxia, and the release of inflammatory mediators which may lead to AKI. The diagnosis of AKI has been carried out using serum creatinine but this examination has many shortcomings, especially in terms of the time of increase in serum creatinine and much influenced by other factors. New biomarkers are expected to have an advantage over serum creatinine, namely kidney injury molecule-1 (KIM-1). This study aims to determine the area under curve (AUC) and the accuracy of KIM-1 for the diagnosis of AKI in polytrauma. This study carried out a diagnostic test using secondary data with a cross sectional design of all secondary data of the study. This study took secondary data from patients with multiple trauma at the emergency room at RSUP Dr. Hasan Sadikin Bandung from January - June 2017, which is the academic leadership grant (ALG) research data. Data was processed by diagnostic tests, and analyzed by receiver operating characteristic (ROC) curves. KIM-1 has a $109.7 \mathrm{ng} / \mathrm{mL}$ cut-off point, sensitivity of $100 \%$, specificity of $88.89 \%$, positive predictive value of $71.4 \%$, negative predictive value of $100 \%$, AUC value of 0.857 and accuracy of $91.3 \%$. The conclusion of this study is that biomarkers of KIM-1 have an AUC value and a good value of accuracy so that it can be used to diagnose AKI more accurately.
\end{abstract}

Keywords: Acute Kidney Injury, Multiple Trauma, Creatinine, Kidney Injury Molecule-1

\section{Introduction}

Trauma is the most common cause of death in the first four decades of life and is still the main public health problem in every country. [1] Polytrauma is a severe injury to an organ that is followed or accompanied by an injury to other organs, for example when two or more severe injuries are found in two or more areas / organs of the body. The international consensus on trauma in Berlin defines polytrauma as two or more severe injuries where one or all of them can be lifethreatening. With a more objective measurement using Injury Severity Score (ISS), the diagnosis of polytrauma is enforced if the ISS value is $\geq 16$. [2]

Hypoxia and hypovolemia often occur in cases of polytrauma, which if not treated immediately with good management can cause a decrease in blood flow in peripheral organs. One consequence of this condition is that kidney dysfunction occurs resulting in acute kidney injury (AKI). The incidence of AKI in the case of polytrauma will increase the incidence of death or mortality. [3]

Acute kidney injury (AKI), formerly known as acute kidney failure (AKF), is a decrease in kidney function characterized by an increase in serum creatinine levels, a decrease in glomerular filtration rate (GFR), and a decrease in urine production determined by the Risk, Injury, Loss, Failure, End-Stage Kidney Disease (RIFLE) and the Acute Kidney Injury Network (AKIN) criteria. [3] An increase in creatinine and a decrease in urine production will occur within a few days after injury. Delay in interventions such as in providing the renal replacement therapy (RRT) can result in increased morbidity and mortality in polytrauma patients. Efforts to reduce morbidity and mortality are done by early 
detections using biological markers (biomarkers) that are able to show a decline in kidney function more quickly without being influenced by factors outside the kidney. [4]

The ideal biomarker characteristics are non-invasive, high in sensitivity and specificity, quick to increase and highly responsive to kidney disease, directly related to kidney damage, and able to provide prognostic value of an illness. Biological markers that can be used for early diagnosis of AKI include cyistatin c, interleukin-18 (IL-18), kidney injury molecule-1 (KIM-1) and neutrophil gelatinase associated lipocalin (NGAL). These biological markers have their respective sensitivity and specificity. [5]

Kidney injury molecule- 1 is a type 1 transmembrane glycoprotein that has an extracellular domain and cytoplasmic domain. KIM-1 is not detected in normal kidneys but is expressed in very high levels by the proximal tubular epithelium in response to epithelial regeneration after kidney damage due to ischemic or toxin. The advantages of KIM-1 examination are its specificity, its ability to be assessed quantitatively, and its examination method that is not difficult and does not take a long time. In developed countries, KIM-1 examination can be examined using analytical tools that are generally available in clinical laboratories. KIM-1 has advantages compared to other markers because the elevated levels of KIM-1 in blood and urine can be obtained 12-24 hours after kidney injury. [6] In humans, plasma KIM-1 levels are higher in patients with AKI compared to healthy controls or patients without AKI heart surgery with the area under the curve (AUC) value of 0.96 . [7] The AUC value has a range between 0 and 1. The area under the curve provides an overview of the comparison of the biomarker capabilities of KIM-1 in the diagnosis of AKI. [8]

The purpose of this study was to determine the AUC value and accuracy of KIM-1 for the diagnosis of AKI in polytrauma patients.

\section{Object and Method}

This research is a diagnostic test with a cross-sectional design using secondary data that meet the research criteria. The object of the study consisted of 23 data from the academic leadership grant (ALG), under the title of "NGAL Prognostic Factors, Cystatin C, KIM-1, IL-18 and $\mathrm{pCO}_{2}$ gap on AKI and Mortality Events in Polytrauma Patients who admitted to the Emergency Department of Dr. Hasan Sadikin Bandung's Central General Hospital," which satisfied the inclusion and exclusion criteria from ALG research subjects.

The inclusion criteria were polytrauma patients, 18-65 years of age, ISS $\geq 16$, and CVP values $\geq 10 \mathrm{~cm} \mathrm{H}_{2} \mathrm{O}$. Exclusion criteria were patients who had a history of chronic kidney disease (CKD), hemodialysis, malignancy, chronic heart abnormalities and diabetes mellitus. The criteria for drop out in this study were ALG research data and incomplete medical records.

After obtaining the approval for the use of data from the main researcher and research permit from the Health
Research Ethics Committee of Dr. Hasan Sadikin Bandung's Central General Hospital / Faculty of Medicine at Padjajaran University, the researchers used part of the ALG research data and medical records of polytrauma patients in the Emergency Room Installation (ERI) of the hospital from January to June 2017. Several data, including age, gender, ISS value, trauma mechanism, CVP value, KIM-1 value, and creatinine value, were subsequently recorded. The obtained data were then recorded and statistical analyses were carried out in accordance with the research objectives and hypotheses, namely to determine the AUC value and accuracy of KIM-1 to diagnose AKI in polytrauma patients at the ERI of the hospital as a marker of AKI.

The AUC value can be used to measure the accuracy of a general diagnostic test with the AUC value range of $0-1$. The AUC value that is closer to 1 indicates that the diagnostic test is getting better. The interpretation of the category of accuracy values is as follows: $50 \%-60 \%$ (very weak), $60 \%-$ $70 \%$ (weak), 70\%-80\% (medium), 80\%-90\% (strong), 90\%$100 \%$ (very strong). While the interpretation criteria for the AUC values are as follows: $>0.5-0.6$ (very weak), $>0.6-0.7$ (weak), > 0.7-0.8 (moderate), > $0.8-0.9$ (good), > 0.9-1 (very good). [9] Statistical tests on the data were processed using SPSS version 24.0 for windows.

\section{Results}

Table 1. Characteristics of Research Subjects

\begin{tabular}{ll}
\hline Variable & $\mathbf{n}=\mathbf{2 3}$ \\
\hline Age (years) & $31.82 \pm 13.364$ \\
Mean \pm Std & 27.00 \\
Median & $18.00-65.00$ \\
Range (min-max) & \\
Gender & 23 \\
Male & 0 \\
Female & \\
Mechanism of trauma & 2 \\
Falling from Height & 19 \\
Traffic accident & 2 \\
Struck down by iron /wreckage & \\
ISS & $21.91 \pm 5.177$ \\
Mean \pm Std & 22.00 \\
Median & $17.00-38.00$ \\
Range (min-max) & \\
CVP (cmH $\left.{ }_{2} \mathrm{O}\right)$ & $14.08 \pm 1.443$ \\
Mean \pm Std & 14.00 \\
Median & $12.00-17.00$ \\
Range (min-max) & \\
Creatinine (mg/dL) & $1.12 \pm 0.481$ \\
Mean \pm Std & 0.90 \\
Median & $0.60-2.20$ \\
Range (min-max) & $92.54 \pm 50.349$ \\
Concentration of KIM -1 (ng/mL) & \\
Mean \pm Std & $59.90-303.46$ \\
Median & \\
Range (min-max) & \\
\hline
\end{tabular}

From 23 subjects, we obtained the characteristics of patients: the average age of $31.82 \pm 13.384$ years, all males, the mechanism of trauma mostly due to traffic accidents, an average of $21.91 \pm 5.177$ for ISS, and the average of 
$14.08 \pm 1.443$ for CVP value. The concentration of KIM-1 has an average of $92.54 \pm 50.349 \mathrm{ng} / \mathrm{mL}$ (Table 1 ).

Table 2. Concentration of KIM-1 dan Cut off Value of KIM-1 in AKI patients based on RIFLE criteria (Creatinine $\geq 1.3$ ).

\begin{tabular}{lll}
\hline Creatinine (mg/dL) & KIM-1 (ng/mL) & NGAL Cut off \\
\hline 1.39 & 75.7 & \\
1.67 & 122.65 & \\
1.72 & 112.84 & $109.70^{*}$ \\
1.81 & 120.11 & \\
2.2 & 117.20 & \\
\hline
\end{tabular}

Notes: * RIFLE Criteria

** Mean from KIM-1 value in AKI sample + based on RIFLE criteria

The cut off value of KIM-1 in this study was determined by the mean / mean value of the KIM-1 value in the AKI sample based on the RIFLE criteria, that is $109.70 \mathrm{ng} / \mathrm{mL}$ (Table 2).

Table 3. Diagnostic Test of AKI.

\begin{tabular}{llll}
\hline KIM-1 Levels & \multicolumn{2}{l}{ Creatinine Levels $(\geq \mathbf{1 . 3} \mathbf{~ m g} / \mathbf{d L})$} & \multirow{2}{*}{ Total } \\
\cline { 2 - 3 } $\mathbf{( \mathbf { 1 0 9 } , \mathbf { 7 0 }}$ & $\mathbf{A K I}+$ & $\mathbf{A K I}-$ & $\mathbf{n}$ \\
\cline { 2 - 4 } $\mathbf{p g} / \mathbf{m L})$ & $\mathbf{n}$ & 2 & 7 \\
\hline AKI + & 5 & 16 & 16 \\
AKI - & 0 & 18 & 23 \\
Total & 5 & & \\
\hline
\end{tabular}

In this study, 5 out of 23 subjects were diagnosed with AKI based on serum creatinine levels, while there were more subjects (7 out of 23 subjects) with AKI based on the increase in KIM-1 levels (Table 3).

The diagnostic test results based on KIM-1 and serum creatinine levels revealed sensitivity value, specificity value, positive predictive value (NDP), negative predictive value (NDN), area under curve (AUC) value and accuracy value. The analysis results using the receiver operating characteristic (ROC) curve revealed the AUC value of 0.857 with $91.3 \%$ accuracy (Figure 1 and Table 4 ).

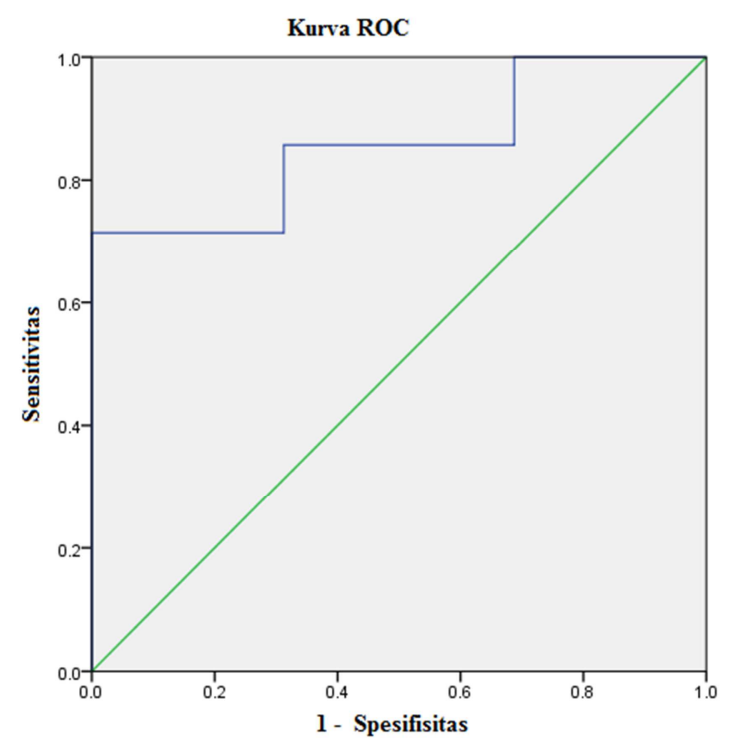

Figure 1. ROC Curve of KIM-1.
Table 4. Results of Diagnostic Test of AKI Based on Examination of KIM-I Levels and Serum Creatinine Levels.

\begin{tabular}{ll}
\hline Diagnostic Test & Diagnostic Value \\
\hline Sensitivity & $100 \%$ \\
Specificity & $88.89 \%$ \\
Positive Predictive Value (PPV) & $71.4 \%$ \\
Negative Predictive Value (NPV) & $100 \%$ \\
Area Under Curve (AUC) Value & 0.857 \\
Accuracy & $91.3 \%$ \\
\hline
\end{tabular}

\section{Discussion}

Table 1 illustrates that the characteristics of patients in this study sample were heterogeneous. The average age of the study subjects was 31.82 years old. The average age is in accordance with the characteristics obtained in the WHO's trauma study that most trauma occur in the productive age (s). The cause of the most trauma in this study was a traffic accident. This is also in accordance with the 2002 WHO's study revealing that the cause of most trauma was a traffic accident. [9]

In this study, the trauma was suffered $100 \%$ by men. The overall incidence of trauma in men is related to traffic accidents being the most recorded mechanism of trauma in this study. It can be argued that the habit of driving motorized vehicles is done more by men. The average ISS value in this study was 21.91 , which is in accordance with the polytrauma criterion on the ISS $(>16)$. [9-11]

In polytrauma, peripheral vasoconstriction, congestion, hypoperfusion and inflammatory mediator release may occur, potentially resulting in kidney damage. The release of inflammatory mediators and cytokines produced by tubular epithelium initiates leukocyte infiltration resulting in microcirculation obstruction. The release of cytokines and free radicals from oxygen by these leukocytes can damage the tubular epithelium resulting in acute tubular necrosis. [12]

If there is an injury to the tubule, the tubular epithelium will be activated and begin the formation of KIM-1 rapidly in the apical membrane of the tubular epithelium. Epithelial damage of the renal tubules will activate the cytoplasmic domain, so that KIM-1 will be released and bind to apotosis/phagocytic cells. Research on mice shows that KIM1 ectodomain functions as a phagocytic receptor that recognizes phosphorylation compounds from tyrosine on the surface of dead cells. The tubular epithelium then protects the dead cell, bringing it to the lysosome so that it can clean the tubular lumen from debris to prevent obstruction. KIM-1 ectodomain can be released carefully with the help of metaloproteinase, but the role of KIM-1 ectodomain released into this lumen is still unknown. [6,7]

Research on the concentration of KIM-1 as a marker of acute tubular necrosis (ATN) was first published in 2002. In the study, it was found that there was a significant increase in the concentration of KIM-1 in renal biopsy specimens of ATN patients and a significant increase in the KIM-1 ectodomain level in the patients' urine. KIM measurements for 1 ATN patient were compared with AKI patients with 
causes other than ischemia and nephrotoxicity. It was found that the concentration of KIM-1 in ATN was higher than that of kidney injury patients with other causes. $[6,13]$

Several studies have reported comparing KIM-1 with urine glucose, urine protein, $\mathrm{N}$-acetyl-b-glucosaminidase, blood urea nitrogen (BUN), and serum creatinine as early diagnostic indicators of AKI. Comparison of KIM-1, BUN, and Serum Creatinine was carried out by examining BUN, creatinine and KIM-1 on days 0,1 and 2 after the examination of cisplatin 5 and $7.5 \mathrm{mg} / \mathrm{kgBB}$. In the group that was given $5 \mathrm{mg} / \mathrm{kgBB}$ and $7.5 \mathrm{mg} / \mathrm{kgBB}$ of cisplatin, on the first day, there was no significant increase in BUN or serum creatinine levels. On the other hand, KIM-1 had increased 3-5 times at the beginning of the first day, and had increased 7-10 times on the second day. This shows that KIM-1 is more sensitive and a significant increase can indicate a kidney injury when other markers cannot predict it. $[6,14]$

The effectiveness of KIM-1 as the initial marker of AKI has been investigated on mice by making bilateral renal ischemia. Increased plasma BUN or creatinine levels do not occur in 10 or 20 minutes of ischemia. BUN levels increase by 4-5 times after 30 or 45 minutes of ischemia, while Serum Creatinine levels increase by 5-6 times. Conversely, KIM-1 increase by 5 times compared to controls after 10 minutes of ischemia. $[6,15]$

Severe long-term renal hypoperfusion will interfere with the authoregulation mechanism of the kidneys with afferent arterioles experiencing vasoconstriction, mesangial contractions emerging and sodium and water reabsorption increasing, as well as impaired creatinine excretion occuring. An examination of serum creatinine levels is an examination used today for the diagnosis of AKI, used to calculate kidney function to assess Glomerular Filtration Rate (GFR). Serum creatinine levels will increase to abnormal limits if the GFR has been lost at least $50 \%$ and it takes up to $48-72$ hours to be detected in the blood. Serum creatinine levels also become normal after 2-3 days of kidney cell repair so that they cannot determine the exact time of kidney damage. From increased serum creatinine levels, it is difficult to distinguish whether the cause is pre-renal, renal or post-renal. In practice, a BUN examination is needed to calculate the $\mathrm{BUN} /$ creatinine ratio. Another disadvantage is that serum creatinine levels are strongly influenced by age, sex, weight, muscle mass, drug metabolism, protein intake and hydration status. $[16,17]$

This research is a diagnostic test that has a dependent variable to be tested based on the examination results. In analyzing the results of a diagnostic test, the sensitivity, specificity, NDP, NDN, AUC and accuracy of the KIM-1 concentration must be determined.

In this study, the results of the diagnostic test showed that the sensitivity of the KIM-1 concentration was $100 \%$, implying that $100 \%$ of subjects with positive laboratory results of the AKI were confirmed to suffer from AKI. The results of the diagnostic test showed that the specificity of the KIM-1 concentration was $88.89 \%$, implying that $88.89 \%$ of patients with negative AKI laboratory tests were confirmed not to suffer from AKI. A negative predictive value of $100 \%$ gives an illustration that if the laboratory test results are negative then $100 \%$ will have no chance to become AKI. A positive predictive value of $71.4 \%$ gives an illustration that if the results of the laboratory tests are positive then $71.4 \%$ will have a chance to become AKI. In the ROC curve, it was found that AUC value of the concentration of KIM-1 was 0.857 , showing that the concentration of KIM-1 in the case of AKI in polytrauma patients had a good diagnostic value. In the study, an accuracy value of $91.3 \%$ was obtained, implying that the accuracy of KIM-1 for the diagnosis of AKI can be classified as good.

The examination of KIM-1 concentration in polytrauma patients has a good AUC value, accuracy, sensitivity, specificity, positive predictive value, and negative predictive value. The results of the study are in accordance with a comparison of plasma KIM-1 levels in post-cardiac surgery patients, in that KIM-1 levels were higher in adult patients with AKI compared to healthy controls or post-cardiac surgery patients without AKI with an AUC value of 0.96. [7, 18] Another study said that KIM-1 levels significantly increased 12 hours after operation in pediatric patients with AKI who underwent cardiac surgery with an AUC value of 0.86 . $[6,18]$ In this study all the results are quite well, but conducted only in a single centre and not to many sample size adopted. I suggest in the future other study will be conducted in multi centre and bigger sample size adopted. The disadvantage of KIM-1 measurenment hasn't been applied in daily clinical practice limited in the laboratory.

\section{Conclusion}

Based on the results and discussion above, the conclusion of this study is that KIM-1 can be used relatively well to establish a diagnosis of AKI in polytrauma patients. KIM-1 more sensitive and more predictive for early diagnosis AKI than creatinin measurment. So, it will be so great if KIM-1 can be used in clinical practice just likes creatinin to diagnose AKI.

\section{References}

[1] World Health Organization. Injuries and violence: the fact; 2014. [diunduh 20 Agustus 2017]. Tersedia dari: http://apps.who.int/iris/handle/10665/149798.

[2] Butcher, NE, Balogh ZJ. Update on the definition of polytrauma. J Trauma Acute Care Surg. 2014; 70 (1): 10711.

[3] Abreu KLS, Junior GB, Barreto AG, Melo FM, Oliveira BB. Acute kidney injury after trauma: Prevalence, clinical characteristics and RIFLE classification. Indian J Crit Care Med. 2010; 14: 121-8.

[4] Molitoris BA, Melnikov VY, Okusa MD, Himmelfarb J. Technology insight: Biomarker development in acute kidney injury - What can we anticipate? Nat Clin Pract Nephrol. 2008; 4 (3): 154-65. 
[5] De Geus HR, Betjes MJ, Bakker J. Biomarkers for the prediction of acute kidney injury: a narrative review on current status and future challenges. Clin Kidney J. 2012; 5: $102-8$.

[6] Rinawati W, Aulia D. Kidney injury molecule-1 (KIM-1) sebagai penanda baru nekrosis tubular akut. Artikel Khusus, Maj Kedokt Indon. 2011; 61 (2).

[7] Sabbisetti VS, Waikar SS, Antoine DJ, Smiles A, Wang C. Blood kidney injury molecule-1 is a biomarker of acute and chronic kidney injury and predicts progression to ESRD in type I diabetes. J Am Soc Nephrol. 2014; 25 (10): 2177-86.

[8] Kalamas AG. Intravenous Fluid and Electrolytes. Dalam: Stoelting RK, Miller RD, penyunting. Edisi ke-7. Basics of anesthesia. Philadelphia: Churchill Livingstone Elsevier; 2018. hlm. 341-51.

[9] Oktaviana Firma. Pola cedera kecelakaan lalu lintas pada kendaraan beroda dua. [diunduh 22 November 2012]; Tersedia dari www.lontar.ui.ac.id/file?fileS-5384-Pola\%20cideraBibliografi.pdf.

[10] Surgical Critical Care. Injury severity score; 2015. [diunduh 20 Agustus 2017]. Tersedia dari: http://www.surgicalcriticalcare.net.
[11] Campion HR. Trauma scoring. Scand Surg. 2012; 91: 12-22.

[12] Bagshaw SM, George C, Gibney RTN, Bellomo R. A multicenter evaluation of early acute kidney injury in critical ill trauma patients. Renal Failure. 2008; 30: 581-89.

[13] Rizvi MS, Kashani KB. Biomarkers for early detection of acute kidney injury. JALM. 2017; 02 (03): 386-99.

[14] Lombi F, Muryan A, Canzonier R, Trimarchi H. Biomarkers in acute kidney injury: Evidence or paradigm? Nefrologia. 2016; 36 (4): $339-46$.

[15] Lawang SA, Pudjiadi A, Latief A. Neutropil gelatinase associated lipocalin urin sebagai deteksi dini AKI. Sari Pediatri. 2014; 16 (3) 195-200.

[16] Brady HR, Brenner BM. Acute Renal Failure. Dalam: Dennis LK, Anthony SF, Dan LL, Eugene B, Stephen LH, Larry J, penyunting. Harrison's Principles of Internal Medicine. Edisi ke-18. New York: McGraw; 2013. hlm. 954-959.

[17] Maskoen TT, Suwarman, Masthura A. Nilai AUC dan akurasi NGAL untuk diagnosis AKI pada pasien politrauma di IGD RSHS. Anesth Crit Care. 2017; 35 (3): 158-64.

[18] Devarajan P. Biomarkers for the Early Detection of Acute Kidney Injury. Current Opinion in Pediatrics. 2011; 23 (2): 194-200. 